\title{
Hazards of Organic Chloride to Petroleum Processing in Chinese Refineries and Industrial Countermeasures
}

\author{
Xiaohui $\mathrm{Li}^{1 *}$, Bencheng $\mathrm{Wu}^{2}$ and Jianhua $\mathrm{Zhu}^{2}$ \\ ${ }^{1}$ Chemistry and Chemical Engineering, Xi'an Shiyou University, China \\ ${ }^{2}$ State Key Laboratory of Heavy Oil Processing, China University of Petroleum, China \\ *Corresponding author: Xiaohui Li, College of Chemistry and Chemical Engineering, Xi'an Shiyou University, Shaanxi 710065, People’s Republic of \\ China.
}

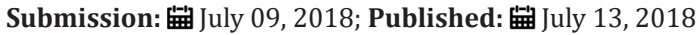

\begin{abstract}
In the petroleum processing, the organic chlorides in crude oil can cause the leakage for chlorine corrosion, the blockage of ammonium chloride crystal, and the poisoning of catalyst, which is a significant challenge to the safe production of clean fuel. The present review paper discusses the present situation of hazards to refining equipments caused by organic chlorides in China's refineries, involving primary processing and secondary processing units. The measures and experiences in preventing organochlorine hazards in Chinese refineries are also introduced.
\end{abstract}

\section{Introduction}

There are two kinds of chlorides in crude oil, one is inorganic chloride, i.e., inorganic salt and the other is organic chloride. It is known that inorganic chlorides such as $\mathrm{NaCl}, \mathrm{MgCl}_{2}, \mathrm{CaCl}_{2}$, etc. in crude oil can cause equipment corrosion and clogging of ammonium chloride, it can be removed by electric desalting before atmospheric distillation [1]. Generally, the salt content of the desalted crude is no more than $3 \mathrm{mg} / \mathrm{L}$ in the Chinese refineries. The feed oil of FCC, delayed coking, hydro-cracking unit can also be desalting through electric desalination if the content of inorganic chlorine is as high as more than the permitted value. Even if the content of inorganic chlorine in crude oil is very low after desalination, a serious chlorine corrosion and ammonium chloride crystallization will still occur. So, the main culprit is the organic chloride which cannot be removed by electric desalting [2]. There are mainly two types of organochlorine compounds in crude oil, one type is the naturally occurring as the inherent components of crude oil [3], while another type is artificially added as the foreign matter during crude oil exploitation [4], transportation [5] and refining [6]. These organic chlorides tend to convert into hydrogen chloride ( $\mathrm{HCl}$ ) during the crude oil refining process such as distillation, FCC, hydrogenation, delayed coking, etc. Then, this $\mathrm{HCl}$ dissolved into a tiny amount of water to form a dilute hydrochloric acid solution, which, in turn, results in a serious corrosion to the top section of the distillation column and overhead condensing system [7-9]. Moreover, the organic chlorides can form $\mathrm{HCl}$ in hydrogenation process, i.e., $\mathrm{HDCl}$ (hydrodechlorination). $\mathrm{HCl}$ can react with $\mathrm{NH}_{3}$ formed by HDN (hydrodenitrogenation) to form ammonium chloride $\left(\mathrm{NH}_{4} \mathrm{Cl}\right) . \mathrm{NH}_{4} \mathrm{Cl}$ can lead to a serious blockage to the heat exchanger [6] and under-deposit corrosion [10,11]. Since in June 2013, due to the processing of high organochlorine crude oil the equipments of some refineries in China suffered from ammonium chloride blockage and corrosion, which caused production shrink or shutdown.

a) Distillation tower: the tower top, trays, pipelines of tower top and heat exchanger. Because ammonia salt and/or chloride amine salts are condensed from vapor phase and further congealed as salt sediment which occurred at low temperature and low flow area. At this time, the reflux system at the top of tower will be affected, leading to a bad operation of the whole tower.

b) FCC (Fluidized catalytic cracking) and delayed coking: the top and recirculation system of fractionator suffered from ammonium chloride corrosion and salinization.

c) Catalytic reforming unit: The outlet of pre-hydrogenation reactor and recycle hydrogen system. The formed $\mathrm{NH}_{4} \mathrm{Cl}$ will cause pitting and scaling at the top of the stabilizer tower or depentane tower.

d) Hydrogenation unit: the outlet of hydrogenation reactor suffers from blockage and corrosion of ammonium chloride. 
Also, many parts, such as the feed side of discharge of heat exchanger, the inlet of air cooling system, circulating hydrogen compressor, thermal high pressure separator, pipes at the top of a stripping tower, etc. were all found salt deposition of ammonium chloride and corrosion.

\section{Countermeasures}

The processing of high chlorinated crude oil is a thorny problem, which poses a big challenge to technicians in refineries. Next, we will introduce the industrial practice and some successful experience in processing high chlorinated crude oil and anticorrosion measures of Chinese refineries in recent years. As the main source of organochlorine in crude oil is the chlorinated chemical additives added to the oil field, so the most fundamental measure for reducing organic chlorides in crude oil is to eliminate use of various kinds of chlorine-containing oilfield chemicals, especially oil soluble chemical additives containing chlorine.

\section{Atmospheric and vacuum distillation tower}

a. The crude oil with high content chlorine should be blended with crude oil with zero or low content chlorine. The total chlorine content of the mixed crude oil is controlled below $30 \mathrm{mg} / \mathrm{kg}$ [12].

b. Remove organic chlorides from crude oil by using chlorine transfer agent [13].

c. When ammonia injection in distillation tower top, the ammonia can be replaced as organic amines for injection. Organic amines have better neutralization and corrosion inhibition effect which can effectively inhibit the crystallization of $\mathrm{NH}_{4} \mathrm{Cl}$ and dew point corrosion and scale corrosion at low temperature [13]. Improve temperature at the top of distillation tower appropriately. This temperature should be controlled over $5 \mathrm{~K}$ above vapor saturation temperature at the corresponding water vapor pressure, ensuring that no liquid water is formed [13].

d. Heat-removing process of top circulating reflux system is adjusted to increase the temperature of circulating reflux, so that it will not drop below the dew point of steam and reduce the chance of steam condensation [13].

e. The water washing line is added to the inlet of air cooler at the distillation tower. When the pressure between the distillation tower and the gasoline tank is found to be increased, a proper amount of softened water is introduced to the top of the distillation tower through water washing line, then, the $\mathrm{NH}_{4} \mathrm{Cl}$ salt dissolves in the water and enters the top liquid separation tank of the tower and is sent out by the pump [13].

\section{FCC}

a) Pay attention to controlling the chlorine content of feed oil; establish the linkage mechanism of the atmospheric distillation and FCC. The operation experience showed that the crystallization of $\mathrm{NH}_{4} \mathrm{Cl}$ would not be formed when chlorine content of FCC feed was less than 6.0mg/L [14]. b) When the content of FCC feed is more than $6 \mathrm{mg} / \mathrm{L}$, the temperature of the tower top should be increased and the amount of steam injected into the reaction system can be reduced. The dry gas can be used as pre lifting gas to replace the steam, and the amount of steam injected into the fractionator should be cut to decrease the partial pressure of the steam at the tower top, so that the steam can go out from the top of the tower, thus reduce the formation of liquid water and prevent the intensification of $\mathrm{NH}_{4} \mathrm{Cl}$ crystallization [14].

c) The proper operation temperature of fractionating tower top should be selected carefully, and the temperature of reflux and side stream should be controlled appropriately. The temperature of the fractionating tower top should not be too low, usually not less than $110{ }^{\circ} \mathrm{c}$. Control the temperature of the fractionating tower top at above $5{ }^{\circ} \mathrm{C}$ of the formation temperature of the liquid water.

d) If the chlorine content continues exceeding the standard, it is necessary to wash the top of fractionator regularly. Which can effectively reduce the $\mathrm{NH}_{4} \mathrm{Cl}$ crystallization $[15,16]$.

e) When the properties of the feed are constant and there is no operation fluctuation, if the dry point of gasoline is rising, at this time, increase the amount of heat removal from the top of the tower. After done this, if the dry point cannot be reduced, or the decrease is not obvious, then, it means that at this point the amount of $\mathrm{NH}_{4} \mathrm{Cl}$ salt is small, and it is the best time to remove salt by water washing [14].

\section{Hydrogenation unit}

a. De-chlorination of feed oil. The dynamic monitoring of chlorine ion in crude oil and side line distillates was carried out. The chlorine ion in feed diesel oil should be strictly controlled at no more than $10 \mathrm{mg} / \mathrm{L}$ or even lower $(2 \mathrm{mg} / \mathrm{L})$ also reduce the water content in feed as much as possible $[17,18]$. Adsorption de-chlorination is a useful method [19]. De-chlorination agents also can be used to transform organochlorine salts into inorganic chloride salts and to be washed into the water phase [20].

b. Adding high temperature corrosion inhibitor in high pressure water injection can effectively reduce the scaling and corrosion of high pressure heat exchange system of hydrogenation unit [21]. It is suggested that $0.5 \%$ Mannich base and sodium silicate can be combined as a corrosion inhibitor to form a protective film on the surface of the metal, thus decrease corrosion caused by ammonium salts [19].

c. The crystallization temperature of ammonium chloride is generally $150 \sim 200{ }^{\circ} \mathrm{C}$. Pay attention to the crystallization temperature and avoid the crystallization temperature zone. So Increase the inlet temperature of thermal high pressure separator to above $240{ }^{\circ} \mathrm{c}$, establish the monitoring data of the crystallization temperature of the ammonium chloride, and adjust the operating temperature to control the ammonium chloride was crystallized at the reasonable location so as to ensure the long period operation $[17,22,23]$. 
d. The outlet of the pressure gauge of heat exchanger need to be kept warm to ensure that the temperature of this position does not decrease, so as to prevent the chloride ions aggregation and corrosion [19].

e. Increase the water injection in the high-pressure air cooler [19], heat exchanger [21,24] to improve the washing efficiency of ammonium chloride.

f. The stress of welding part should be eliminated to prevent weld corrosion cracking [19].

g. Upgrade the material of heat exchanger system to improve corrosion resistance. The dual phase stainless steel has a high strength, inter-granular corrosion resistance and chloride stress corrosion resistance, and molybdenum containing duplex stainless steel also has good corrosion resistance, which is an ideal upgrading material [19].

\section{Catalytic reforming unit}

In the rear of the pre hydrogenation reactor, two de-chlorination devices in series or parallel are added, and the chlorine elements that cause corrosion are removed by the adsorption of de-chlorination agent. The corrosion inhibitor is added to the pre-hydrogenating site to form a film on the metal surface for preventing corrosion [25].

\section{Delayed coking unit}

By means of electric desalting technology and injection of organic amines on the top of fractionating tower, the content of chloride ion is reduced. Moreover, the accumulation of $\mathrm{NH}_{4} \mathrm{Cl}$ particles is avoided by injecting demulsifier and de-aerated water on the top of the fractionating tower. The formation of liquid water can be reduced by decreasing the top pressure, raising the temperature of the tower top. By these measures, the phenomenon of $\mathrm{NH}_{4} \mathrm{Cl}$ deposition on the fractionating tower tray and tower top were effectively suppressed, and the operation period of the unit is prolonged [26,27]

\section{Conclusion}

The hazards caused by organic chlorides in refineries was mainly ammonium chloride clogging and the corrosion to equipments, involving primary processing and secondary processing units. Several main principles to prevent organochlorine hazards took by Chinese refineries were:

a. Eliminate the use of various kinds of chloro-chemical agents adding in the oil recovery process.

b. The crude oil with high content chlorine need to be blended with crude oil with zero or low content chlorine.

c. In petroleum processing, pretreatment for chlorine removal of feed oil may be necessary.

d. Focus on the ammonium chloride crystallization temperature and avoid this temperature zone by taking corresponding measures. e. Adding high temperature corrosion inhibitor, injection of organic amines is better.

f. Increase the water injection to achieve a good washing to ammonium chloride.

g. Upgrade the material of refining equipments to improve corrosion resistance.

h. Establish real-time monitoring mechanism to chlorine in crude oil processing.

\section{Acknowledgement}

The authors would like to acknowledge funding for this project from Petro China Innovation Foundation (No. 2016D-5007-0404), and Natural Science Basic Research Plan in Shaanxi Province of China (No. 2017JQ2034).

\section{References}

1. Wu BC, Li XH, Li YF, Zhu JH, Wang J (2016) Hydrolysis reaction tendency of low-boiling organic chlorides to generate hydrogen chloride in crude oil distillation. Energy Fuels 30(2): 1524-1530.

2. Wu BC, Li YF, Li XH, Zhu JH, Ma R, et al. (2018) Organochlorine compounds with a low boiling point in desalted crude oil: identification and conversion. Energy Fuels 32(6): 6475-6481.

3. Ma R, Zhu JH, Wu BC, Xue JX (2016) Distribution and hazards of organic chlorides in crude oil and its distillates. Petroleum Refinery Engineering 46(4): 60-64.

4. Zhang XJ (2004) Sources and distribution of chlorides in crude and the control measures. Petroleum Refinery Engineering 34 (2):14-16.

5. Gutzeit J (2000) Effect of organic chloride contamination of crude oil on refinery corrosion. NACE International, Houston, Texas, USA.

6. National Association of Corrosion Engineers (2004) Effect of Nonextractable Chlorides on refinery Corrosion and Fouling. NACE International, Houston, Texas, USA.

7. Wu BC, Li YF, Zhu JH (2014) Insight to origins of component hydrogen chloride in distillation process of crude oil. Acta petroleisinica 30(6): 1034-1042.

8. Gray MR, Eaton PE, Le T (2008) Inhibition and promotion of hydrolysis of chloride salts in model crude oil and heavy oil. Petroleum Science and Technology 26(16): 1934-1944.

9. Seadat-Talab M, Allahkaram SR (2013) Failure analysis of overhead flow cooling systems of a light naphtha separator tower at a petrochemical plant. Engineering Failure Analysis 27(1): 130-140.

10. Sun A, Fan D (2010) Prediction, monitoring, and control of ammonium chloride corrosion in refining processes. NACE International, San Antonio, Texas, USA.

11. Zhai ZQ (2015) Analysis of corrosion causes of overhead tray of delayed coker fractionator and improvement measures. Corrosion \& Protection in Petrochemical Industry 32(4): 49-53.

12. Tan PQ (2015) Corrosion of crude oil containing chlorine and protection. Corrosion \& Protection in Petrochemical Industry 32(5): 18-21.

13. Chan S (2013) Study on harm of chloride in crude oil for distillation tower and the controlling measures. Technology \& Economics in Petrochemicals 29(3): 39-43.

14. Guo YM, Yang ZD (2016) Causes of salt formation in fractionating tower of FCC and treatment measures. Chemical Enterprise Management 12: 71-73. 
15. Wang WC, Li XG (2010) Online processing of salt coagulation in fractioning column of RFCC unit. Modern Chemical Industry 30(4): 8284.

16. Liu KF, Han JM (1994) Analysis of salt deposition problem in the fractionators of heavy oil catalytic cracker and countermeasures. Petroleum Processing and Petrochemicals 25(1): 46-49.

17. Zhang Y, Li WY, Han CW, Zhu DL (2016) Impact of ammonia chloride crystallization on long-term operation of hydro-treating units. Corrosion \& Protection in Petrochemical Industry 33(4): 29-32.

18. Xing XJ, Yang MH, Jiang YJ, Cao ZH, Zhu SH (2015) Summary of highchlorine crude oil processing. Petroleum Refinery Engineering 45(1): 7-10.

19. Chen XB (2016) Analysis on causes of corrosion of aviation kerosene hydrogenation unit and the anti-corrosion proposals. Technology \& Economics in Petrochemicals 32(3): 48-51.

20. Wang GQ (2014) Corrosion of high-pressure heat exchanger in hydrocracking unit and prevention. Corrosion \& Protection in Petrochemical Industry 31(3): 38-43.

21. Wu ZH (2016) Analysis on the corrosion leakage of high pressure heat exchanger for hydrogenation and countermeasures. Petrochemical Safety Technology 32(2): 20-22.
22. Shang M, Yang JH, Sun T (2016) Impact of high-chloride crude oil on diesel hydro-treating unit and countermeasures. Petroleum Refinery Engineering 46(4): 17-21.

23. Chen XB (2016) Cause analysis of corrosion in jet fuel hydro-treating unit and countermeasures. Corrosion \& Protection in Petrochemical Industry 33(5): 20-24.

24. Li QL, Chen YX, Yang DC (2016) Study on salt deposition and water washing for diesel hydro-treating unit. Petroleum Refinery Engineering 46(11): 29-31.

25. Wang G (2015) Corrosion in pre-hydro-treating system of continuous catalytic reforming unit and prevention. Corrosion \& Protection in Petrochemical Industry 32(4): 18-21.

26. Hou JC, Xu X (2014) Commercial application of new desalting technology in delayed coker fractionator. Petroleum Refinery Engineering 44(9): 13-16.

27. Wu WJ, Duan BX, Jia BY (2014) Analysis of causes of salt deposition in the fractionator overhead of delayed cooking unit and countermeasures. Petroleum Refinery Engineering 44(10): 35-38.
Creative Commons Attribution 4.0 International License

For possible submissions Click Here

\section{Submit Article}

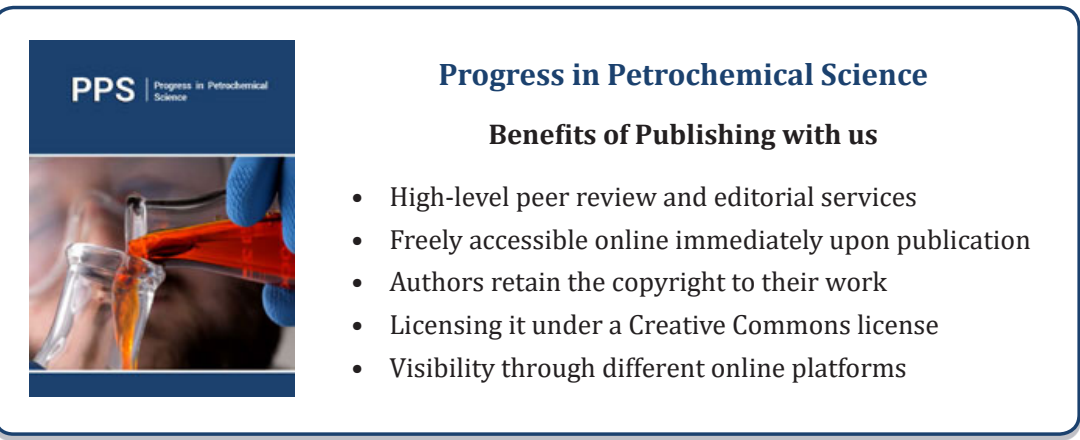

